\title{
Intrauterine Foetal Death and Its Probable Causes: Two Years Experience in Dhulikhel Hospital - Kathmandu University Hospital
}

\section{Tamrakar SR, Chawla CD}

Department of Obstetrics and Gynaecology

Dhulikhel Hospital - Kathmandu University Hospital

Kathmandu University School of Medical Sciences (KUSMS)

Dhulikhel, Kavre, Nepal

\section{Corresponding Author}

Suman Raj Tamrakar

Department of Obstetrics and Gynaecology

Dhulikhel Hospital - Kathmandu University Hospital

Kathmandu University School of Medical Sciences (KUSMS)

Dhulikhel, Kavre, Nepal

E-mail: drsuman537@yahoo.com

\section{Citation}

Tamrakar SR, Chawla CD. Intrauterine Foetal Death and its Probable Causes: Two year Experience in Dhulikhel Hospital - Kathmandu University Hospital. Kathmandu Univ med J 2012;10(4):44-48.

\section{ABSTRACT}

\section{Background}

World health Organization definition of intrauterine foetal demise encompasses any abortion or fetal demise prior to expulsion from its mother, and recommends different protocols according to gestational age. However, conventionally and also in our institution, foetal demise prior to 28 weeks of gestation is managed as abortion in a manner different from foetal demise post 28 weeks of gestation.

\section{Objective}

To find the incidence and characteristics of pregnancies that resulted in stillbirths.

\section{Methods}

A retrospective study, done in Dhulikhel Hospital, Kathmandu University Hospital in the year 2010 and 2011, among 4219 deliveries and 97 fetal deaths. Cases of multiple pregnancy and fetal death diagnosed by ultrasound before the $28^{\text {th }}$ week of gestation were excluded. The included intrauterine foetal demise cases $(n=90)$ were compared with a control group of randomly selected pregnancies $(n=537)$ delivered during the same time period. Assumed predictors of stillbirth were examined through inferential ways (Chi square, $t$ test) using SPSS Version 13.0 for Windows.

\section{Results}

Incidence of intrauterine foetal demise was $2.13 \%$ in the year 2010 and 2011. Mothers in the stillbirth group were slightly older than mothers of live-born infants $(25.47 \pm 5.64$ years vs $23.62 \pm 4.31$ years, $p$ value $=0.000)$. A slightly higher proportion of women in the stillbirth group were of Tamang ethnic origin and primiparous ( $p$ $=0.011,0.000)$. Foetus expelled after IUFD had lower weight compared to live births, $(2925.14 \pm 444.14$ gram vs $2182.78 \pm 821.04$ gram, $p=0.000)$ for gestational age. The stillborn babies were generally born at an earlier gestational age, as would be expected $(p=0.000)$. Incidence of intrauterine foetal demise gradually decreases as parity advances. The incidence was higher in patients receiving antenatal care outside Dhulikhel Hospital, Kathmandu University Hospital.

\section{Conclusions}

While comparing the subject with the theme of the national conference of Nepal Society of Obstetricians and Gynaecologist, most of the cases were mother not receiving antenatal care or those receiving antenatal care in the periphery, There is no denying that there would be a massive improvement in women's health if the co-ordination between the peripheral health care center and tertiary care center was to be improved.

\section{KEY WORDS}

Gestational age, intrauterine foetal death (IUD), parity 


\section{INTRODUCTION}

Intrauterine foetal death (IUFD) is a heartbreaking and tragic event. It remains one of the areas of obstetrics in which improvements could be made. According to WHO, IUFD is defined as deathprior to the complete expulsion or extraction from its mother of a product of conception after the age of viability (according to American College of Obstetricians and Gynecologists, ACOG 22 weeks). ${ }^{1,2}$

\section{Classification}

Early: $<20$ weeks of gestation

Intermediate: 20-27 weeks

Late: $>27$ weeks

Causes occurring before 28 weeks of gestation are usually called missed abortion while those occurring later in antenatal period are usually termed as stillbirths. Hence the cases with $>28$ weeks of gestations are included in this study. There were no IUFD related studies conducted in Nepal till now.

The aim of this study was to find the incidence and characteristics of pregnancies that resulted in stillbirths.

\section{METHODS}

Dhulikhel Hospital, Kathmandu University Hospital (DH$\mathrm{KUH}$ ), performs around 2100 deliveries per year. In the year 2010 and 2011, there were 4219 deliveries and 97 fetal deaths. Of these, 90 stillbirths were singleton pregnancies. Cases of multiple pregnancy $(n=7)$ and fetal death diagnosed by ultrasound before the 28th week of gestation were excluded. The included IUFD cases were compared with a control group of pregnancies ( $n=$ 537) delivered during the same time period, which were randomlyselected.Both groups derived from the same geographic population.

Pregnancy and maternal characteristics related data were retrieved from out-patients clinic and labour registry of the hospital. Maternal characteristics which included ethnic origin, age and parity and fetal factors that included birth weight, sex, and gestational agewere studied. Postmortem examination of dead foetus after delivery was not performed.

Assumed predictors of stillbirth were examined through inferential statistics (Chi square, t test) using SPSS Version 13.0 for Windows.

\section{RESULTS}

An initial univariate analysis was performed to identify factors that seemed to be associated with stillbirth.

Mothers in the stillbirth group were slightly older than mothers of live-born infants $(25.47 \pm 5.64$ years $\mathrm{v} / \mathrm{s}$ $23.62 \pm 4.31$ years, $p$ value $=0.000$ ) (Table 1$)$.
Table 1. (Maternal Characteristics) shows the characteristics for the stillbirth and live birth groups.

\begin{tabular}{|c|c|c|c|}
\hline Variables & IUFD (n=90) & Control $(n=537)$ & $P$ value \\
\hline $\begin{array}{l}\text { Maternal } \\
\text { age }\end{array}$ & $25.47 \pm 5.64$ years & $23.62 \pm 4.31$ years & $0.000 * *$ \\
\hline Caste & $\begin{array}{l}\text { Brahmin-16.7\%, } \\
\text { Chhetri-18.9\%, } \\
\text { Newar-13.3\%, } \\
\text { Tamang-28.9\%, } \\
\text { Lower caste-7.8\%, } \\
\text { Others-14.44\% }\end{array}$ & $\begin{array}{l}\text { Brahmin-27.6\%, } \\
\text { Chhetri-18.3\%, } \\
\text { Newar-20.3\%, } \\
\text { Tamang-17.5\%, } \\
\text { Lower caste-6.9\%, } \\
\text { Others-9.5\% }\end{array}$ & \\
\hline Address & $\begin{array}{l}\text { Kavre-55.6\%, Sindhu- } \\
\text { palchowk-31.1\%, Kath- } \\
\text { mandu Valley-4.44\%, } \\
\text { Dolakha, Ramechhap, } \\
\text { SIndhuli-7.8\%, Oth- } \\
\text { ers-1.1\% }\end{array}$ & $\begin{array}{l}\text { Kavre-75.4\%, Sind- } \\
\text { hupalchowk-14.0\%, } \\
\text { Kathmandu Val- } \\
\text { ley-6.7\%, Dolakha, } \\
\text { Ramechhap, } \\
\text { SIndhuli-2.2\%, Oth- } \\
\text { ers-1.7\% }\end{array}$ & \\
\hline Parity & $\begin{array}{l}\text { Para1-40\%, Para } \\
\text { 2-27.8\%, Para 3-21.1\%, } \\
\text { Para 4-5.6\%, } \geq \text { Para } \\
5-5.6 \%\end{array}$ & $\begin{array}{l}\text { Para } 1-61.8 \%, \\
\text { Para } 2-24.2 \% \text {, } \\
\text { Para } 3-9.3 \% \text {, Para } \\
4-2.8 \%, \geq \text { Para } \\
5-1.9 \%\end{array}$ & \\
\hline
\end{tabular}

Table 2. Comparison of different variables.

\begin{tabular}{|c|c|c|c|c|}
\hline & IUFD (n=90) & $\begin{array}{l}\text { Control } \\
(n=537)\end{array}$ & Total & P value \\
\hline \multicolumn{4}{|l|}{ Caste } & \multirow{3}{*}{$0.011^{*}$} \\
\hline Tamang & $26(21.7 \%)$ & $94(78.3 \%)$ & 120 & \\
\hline Non-Tamang & $64(12.6 \%)$ & $443(87.4 \%)$ & 507 & \\
\hline \multicolumn{4}{|l|}{ Parity } & \multirow{3}{*}{$0.000 * *$} \\
\hline Primi & $36(9.8 \%)$ & $332(90.2 \%)$ & 368 & \\
\hline Multi & $54(20.8 \%)$ & $205(79.2 \%)$ & 259 & \\
\hline \multicolumn{5}{|l|}{ District } \\
\hline Sindhu & $28(27.2 \%)$ & $75(72.8 \%)$ & 103 & \multirow[t]{2}{*}{$0.000 * *$} \\
\hline Non-Sindhu & $62(11.8 \%)$ & $462(88.2 \%)$ & 524 & \\
\hline \multicolumn{5}{|l|}{ ANC } \\
\hline $\mathrm{DH}$ & $29(11.6 \%)$ & $220(88.4 \%)$ & 249 & 0.117 \\
\hline $\begin{array}{l}\text { Outside/ } \\
\text { no ANC }\end{array}$ & $61(16.1 \%)$ & $317(83.9 \%)$ & 378 & \\
\hline Total & $90(14.4 \%)$ & $537(85.6 \%)$ & 627 & \\
\hline
\end{tabular}

A slightly higher proportion of women in the stillbirth group were of Tamang ethnic origin andprimiparous, which was statistically significant $(p=0.011)$ (Table 2).About one third IUFD were from Sindhupalchowk District $(p=0.000)$ (Table 2).

The stillborn babies were generally born at an earlier gestational age, as would be expected $(p=0.000)$ (Table 4). Forty babies (44.4\%) were preterm, 31 babies (34.4\%) were term, 17 babies (18.9\%) were postdated and two babies (2.22\%) were post-term. The fetal sex does not appear to contribute $(p=0.122)$ (Table 4).

Most of the women with stillbirth presented to the hospital with the complaints of reduced fetal movement 
Table 3. (Fetal Characteristics) shows the differences in fetal characteristics between the 2 groups.

\begin{tabular}{|c|c|c|c|}
\hline Variables & IUFD $(n=90)$ & Control $(n=537)$ & $P$ value \\
\hline $\begin{array}{l}\text { Gestational } \\
\text { age }\end{array}$ & $\begin{array}{l}\text { Preterm-44.4\%, } \\
\text { Term-34.4\%, Post- } \\
\text { dated-18.9\%, Post- } \\
\text { term-2.2\% }\end{array}$ & $\begin{array}{l}\text { Preterm-6.52\%, } \\
\text { Term-47.5\%, } \\
\text { Postdated-42.8\%, } \\
\text { Postterm-3.2\% }\end{array}$ & \\
\hline Foetal weight & $\begin{array}{l}2182.78 \pm 821.0 \\
4 \text { gram }\end{array}$ & $\begin{array}{l}2925.14 \pm 444.1 \\
\text { 4gram }\end{array}$ & $0.000 * *$ \\
\hline Foetal gender & $\begin{array}{l}\text { Male-61.1\% } \\
\text { Female-38.9\% }\end{array}$ & $\begin{array}{l}\text { Male-52.3\% } \\
\text { Female-47.7\% }\end{array}$ & \\
\hline
\end{tabular}

Table 4. Comparison of different variables.

\begin{tabular}{|c|c|c|c|c|}
\hline Variables & IUFD $(n=90)$ & Control $(n=537)$ & Total & P value \\
\hline \multicolumn{5}{|c|}{ Gestational age } \\
\hline Preterm & $40(53.3 \%)$ & $35(46.7 \%)$ & 75 & \multirow[t]{2}{*}{$0.000^{* *}$} \\
\hline Term & $50(9.1 \%)$ & $502(90.9 \%)$ & 552 & \\
\hline \multicolumn{5}{|l|}{ Gender } \\
\hline Male & $55(16.4 \%)$ & $281(83.9 \%)$ & 336 & \multirow[t]{3}{*}{0.122} \\
\hline Female & $35(12.0 \%)$ & $256(88.0 \%)$ & 291 & \\
\hline Total & $90(14.4 \%)$ & $537(85.6 \%)$ & 627 & \\
\hline
\end{tabular}

$(n=37)$, antepartum hemorrhage $(n=6)$, abnormal vaginal discharge (meconium stained) $(n=3)$ and abdominal pain or preterm labour. Two cases had oligohydramnios and one had polyhydramnios.

It was a tragic moment when few women who came for regular antenatal checkup had IUFD diagnosed when the fetal heart could not be auscultated. Later it was confirmed by ultrasound.

The reason for referral was recorded in 13 cases. Six cases transferred in utero with hand prolapse, one case with shoulder presentation, two cases with transverse lie and one case with history of foetal distress from periphery. Besides these, other two cases referred with obstructed labour, one underwent hysterectomy with bladder repair and another had uterine rupture so underwent subtotal hysterectomy.

Majority of stillborn babies appeared to be nondysmorphic. Two cases were recorded with multiple congenital abnormalities and another one had cleft lip and palate. And 25 other foetuses are macerated.

The majority of women were at low risk. Associated medical disorders included eclampsia $(n=2)$, essential hypertension $(n=2)$ and seropositive $(n=1)$. There was no association between maternal disease and stillbirth rate.

\section{DISCUSSION}

In this case-control study, we tried to identify probable causes of IUFD. Kumari $S$ et al prospectively studied in 12,000 singleton deliveries, of which 258 (2.15\%) babies had cord abnormalities. Nearly $32 \%$ of these cases had fetal distress and $20.5 \%$ had low Apgar score. Of the various cord problems nuchal cord was noted in $79.1 \%$, cordprolapse in $12.4 \%$ and true knots in $3.9 \%$ cases. Perinatal mortality rate with cord problems was $85.27 / 1000$ births. ${ }^{3}$ In our study, 14 cord prolapse, three cases with nuchal cord, one case true knot were seen.

The postmortem examination helps in reaching a true diagnosis after such a tragic event. A total of 55 cases a histopathological examination of placenta was performed in this study, the majority (47, ie, $85.5 \%$ ) were with normal pathology whereas four placentas were with chorangiosis, three placentas with chorioamnionitits and one placenta with features of amnionitis and single uterine artery.

In a study of foetal histology and stillbirth, Genest DR et al estimated that $80 \%$ of all stillbirths are delivered within one week after death. ${ }^{4}$ Bias attributed to differences between fetal weight at time of death and weight at the time of delivery is likely to be limited. ${ }^{5}$ However, in our hospital, most of the stillborns were delivered soon after diagnosis of foetal death (usually within 24 hours). So it should not affect the statistical significance between birth weights of live born baby and IUFD baby.

Efkarpidis $S$ et al found that there is a strong association between foetal growth restriction and stillbirth. An improvement in the identification of intrauterine growth restriction(IUGR) may improve the outcome for some pregnancies. However, the majority of pregnancies complicated by IUFD were apparently low-risk pregnancies in which IUGR was not detected antenatally. ${ }^{6}$

In more than half of the recorded cases (54.7\%) the complaint was of reduced or absent foetal movements. Reduced foetal movements can be associated with adverse fetal outcome. Efkarpidis $S$ et al found that a proportion of women did not have any complaint at all, with $14 \%$ of IUFDs detected on a routine antenatal clinic appointment when the foetal heart was not audible. ${ }^{6}$ In this study, $41.1 \%$ of study cases presented with complaints of decreased foetal movements.

Because of this problem, since 2009 we developed a protocol to induce ladies with previous complaints of decreased foetal movements at term. In the year 2011, 59 cases were induced with such complaints and 39 delivered vaginally and 20 underwent caesarean section for different indications.

Increased BMI was positively associated with stillbirths. There are cases of undiagnosed diabetes in the group of pregnancies that ended in stillbirth as all these women were investigated after diagnosis of foetal death. A prospective study $(n=1598)$ conducted in $\mathrm{DH}-\mathrm{KUH}$ for screening for gestational diabetes performed by using 50 gram glucose and diagnosis were made using Carpenter Couston criteria. Shrestha et al detected incidence of gestational diabetes was $0.75 \%$ at $\mathrm{KUH}^{7}$ 
Previous studies suggest that male fetuses are more likely to suffer from antenatal hypoxia (ante- or intra-partum). Other studies have shown an association of male foetal sex with intra-partum hypoxia (foetal distress) in terms of low Apgar scores at five minutes, low umbilical artery $\mathrm{pH}$, and risk of emergency cesarean section. ${ }^{8-10}$ In this study, of 24 babies delivered through caesarean section, out of which $14(58.3 \%)$ were male.

Previous studies done by Petridou E et al and Parazzini F et al found that there is a possible association between sex of the foetus and risk of stillbirth,but it was not statistically significant in our study $(p=0.122)$ (Table 4)..$^{11,12}$ In a study by Raymond EG et alshowed stillbirth was not associated with primiparitybut it seems that in multiparous women, previous delivery of live birth is a protective feature. ${ }^{13}$ But $40 \%$ cases in our study were primiparous. And the incidence of IUFD gradually decreases as parity advances i.e. para 2(27.78\%), para 3 (21.11), para 4 and para 5 or more (5.56\% each) (Table 1$)$.

In this study, stillbirth was associated with increasing maternal age (IUFD group $25.47 \pm 5.64$ years, control group $23.62 \pm 4.31$ years)(Table 1 ). Other studies have proved that foetal outcome worsens with advancing maternal age. ${ }^{11,13,15}$ There were seven cases of more than 35 years of age in IUFD group and 14 cases in control group eventhough there was no records of an antenatal screening for chromosomal aneuploidy (trisomy 21 , trisomy 13 , and tetrasomy 16 ).

In our study variables like smoking habit and maternal blood group were not studied but some studies have confirmed an association between smoking and risk of stillbirth, but others have not. ${ }^{13,15,16}$

Maternal blood group was found to be associated with stillbirth, thoughit is difficult to explain the association of

\section{REFERENCES}

1. Olyai R, Mittal C. Fetal death. In.Dutta D K, editor. Recent advances in high risk pregnancy. India: Jaypee Brothers Medical Publishers (P) Ltd; 2010. P155-64.

2. ACOG technical bulletin. International Journal of Gyn and Obs 1993;42(3).

3. Kumari S, Saxena A, Monga D, MalikA, Kabra M, Kurray RM. Significance of cord problems at birth. Indian Pediatr 1992 Mar;29(3):301-5.

4. Genest DR, Williams MA, Greene MF. Estimation of the time of death in stillborn fetuses: I. Histologic evaluation of fetal organs: an autopsy study of 150 stillborn. Obstet Gynecol 1992; 80: 575-584.

5. Clausson B, Gardosi J, Francis A, Cnattingius S. Perinatal outcome in SGA births defined by customized versus population-based birthweight standards. Br J ObstetGynaecol 2001; 108: 830-834.

6. Efkarpidis S, Alexopoulos E, Kean L, Liu D, Fay T. Case-control study of factors associated with intrauterine fetal deaths.MedGenMed 2004 May 27;6(2):53.

7. Shrestha A, Chawla CD.The glucose challenge test for screening of gestational diabetes.Kathmandu Univ Med J 2011;34(2)22-5. certain blood groups with IUFD. Some studies by Cohen BH et al have shown an association with maternal blood group $\mathrm{O}$ and stillbirth. ${ }^{17}$ Other studies by Fedrick J demonstrated positive association between maternal blood group $\mathrm{O}$ and low birth weight and a negative one between maternal blood group $A B$ and low birth weight. ${ }^{18}$ Exactbiological mechanism is not known. A possible link between maternal blood group $\mathrm{O}$ and increased thrombotic predisposition could offer an explanation. ${ }^{18}$

\section{CONCLUSION}

Pregnancies associated with reduced foetal activity warrant careful assessment of foetal wellbeing and should not be considered as low risk. Certainly in the presence of reduced foetal movements, ultrasound assessment is better than cardiotocography.

Increased maternal age is associated with higher rates of IUFD. This is a difficult issue, as there is no age at which the risk becomes definitive; rather there is a gradual increase in risk from the end of the third decade.

The postmortem examination of IUFD foetus showed significant unexpected abnormalities and confirmed the ultrasonographic suspicion. Hence it is indicated in such tragic events whenever cause is unknown as it helps in planning of future pregnancies.

\section{ACKNOWLEDGEMENTS}

We would like to thank Intern Sonam Rinchen Lama, Intern Subas Rai, Intern Sabina, Intern Suresh Ranabhat, Associate Prof Dr Ramesh Makaju (Pathology Department) and Mr Seshananda Sanjel for their assistance and contribution.
8. Hoffmann AL, Hjortdal JO, Secher NJ, Weile B. The relationship between Apgar score, umbilical artery $\mathrm{pH}$ and operative delivery for fetal distress in 2778 infants born at term. Eur J ObstetGynecolReprod Biol 1991; 38: 97-101.

9. Lau TK, Chung KH, Haines CJ, Chang AM. Fetal sex as a risk factor for fetal distress leading to abdominal delivery. Aust N Z J ObstetGynaecol 1996; 36: 146-149.

10. Lieberman E, Lang JM, Cohen AP, Frigoletto FD, Acker D, Rao R. The association of fetal sex with the rate of cesarean section. Am J Obstet Gynecol 1997; 176: 667-671.

11. Petridou E, Kotsifakis G, Revinthi K, Polychronopoulou A, Trichopoulos D. Determinants of stillbirth in Greece. SozPraventivmed.1996; 41: 70-78.

12. Parazzini F, Pirotta N, La Vecchia C, Bocciolone L, Fedele L. Determinants of perinatal and infant mortality in Italy. Rev EpidemiolSantePublique 1992; 40: 15-24.

13. Raymond EG, Cnattingius S, Kiely JL. Effects of maternal age, parity and smoking on the risk of stillbirth. Brit J ObstetGynaecol 1994; 101: 301-306.

14. Ogunyemi D, Jackson U, Buyske S, Risk A. Clinical and pathological correlates of stillbirths in a single institution. ActaObstetGynecol Scand 1998; 77: 722-728. 
15. Cnattingius S, Forman MR, Berendes HW, Isotalo L. Delayed child bearing and risk of adverse perinatal outcome. A population-based study. JAMA 1992; 268: 886-890.

16. Cnattingius S, Haglund B., Kramer MJ. Differences in late fetal death rates in association with determinants of small for gestation age fetuses: population based cohort study. BMJ 1998; 316: 1483-1487.
17. Cohen BH, Sayre JE. Further observations on the relationship of maternal ABO and Rh types to fetal death. Am J Hum Gen 1968; 20: 310-360.

18. Fedrick J, Adelstein P. Factors associated with low birth weight of infants delivered at term. Br J ObstetGynaecol 1978; 85: 1-7. 